\title{
Management of irritable hip: a review of hospital admission policy
}

\author{
G R Taylor, N M P Clarke
}

\begin{abstract}
The case notes of all children admitted during the preceding five years for observation with painful hips (509 patients) were analysed to determine significant diagnostic factors and thus to design an admission policy. Most orthopaedic disorders (62 patients) were apparent on the initial radiographs, with the important exception of osteomyelitis/septic arthritis (21 patients). The remaining 426 patients were diagnosed by exclusion as having an irritable hip. The latter two groups were similar with respect to age, sex, and duration and nature of symptoms. A number of clinical features and laboratory investigations recorded within 12 hours of admission, however, were shown to have significant discriminative value. These were severe spasm, tenderness, pyrexia $\geqslant 38^{\circ} \mathrm{C}$, and an erythrocyte sedimentation rate of $\geqslant 20 \mathrm{~mm} /$ hour (the white cell count was not significant). Combination of any two of these produced a specificity and sensitivity for sepsis of $91 \%$ and $95 \%$ respectively $(95 \%$ confidence interval 0.64 to 0.97 ). A protocol designed from this data analysis is now being tested and is expected to result in a significant reduction in admission rates.

(Arch Dis Child 1994; 71: 59-63)
\end{abstract}

Irritable hip is generally considered to be a diagnosis of exclusion. ${ }^{1-5}$ It was first described by Lovett and Morse in 1892 and subsequent work has further characterised the disorder. ${ }^{1-10}$ Despite the efforts of several groups working prospectively, its aetiology remains obscure and no investigation has proved diagnostic. ${ }^{51-15}$ It is apparent from published work that it is a self limiting disorder of variable severity, and there is little evidence that it results in any long term adverse effects. In the only three long term studies published, a slightly higher likelihood of coxa magna (radiological enlargement of the femoral head) was shown, though the number of cases was small and the significance uncertain. ${ }^{7816}$

It is agreed that whatever its pathology, the danger when treating irritable hip is that of confusing it with a more serious disorder such as septic arthritis, Perthes' disease, late presenting congenital hip dysplasia, or slipped femoral epiphysis, thus delaying appropriate and timely treatment. With this in mind, orthopaedic surgeons recommend prompt referral and many orthopaedic units have adopted a policy of admission and investiga- tion of all children with painful hips. Where outpatient 'observation' has been proposed, specialised investigations have been used - for example, ultrasound - along with frequent review. ${ }^{17}$ Although imaging using ultrasound or tomography is useful in showing an effusion, this is not diagnostic as various hip disorders give rise to this, and osteomyelitis may not. ${ }^{17}$ 18-22 Bone scintigraphy may help in identifying osteomyelitis, but it is not $100 \%$ specific and neither is it a practical proposition for the large number of patients referred with mild symptoms. ${ }^{23-26}$ The admission and treatment of irritable hip with traction/bed rest has never been shown to be prognostically beneficial, although until the 1960s such patients were often kept in hospital for many weeks. ${ }^{127}$ Several workers have measured intracapsular pressures on children in traction and have expressed concern over increases in pressure with skin traction in extension, potentially harmful to the epiphysis. ${ }^{13} 15$

Our primary concern has been to distinguish painful hips due to sepsis from other disease and therefore there has been a policy of admission, traction/bed rest, and investigation. This report is an audit of this practice over the past five years, representing the largest ever series of admissions for irritable hip and comparing them with hip disorders which presented concurrently.

The value of some of the commonly used investigations such as erythrocyte sedimentation rate (ESR), white cell count, temperature, and radiographs is a source of conflicting opinion in published work. ${ }^{4} 101114152728$ One aim of this review was to determine which clinical features and laboratory investigations might be used to develop a less stringent admission policy without placing undue reliance on the use of specialised tests or frequent outpatient attendance, or both. The resulting protocol is currently being tested prospectively.

\section{Patients and methods}

The admission records were examined of all children admitted over a five year period with a hip disorder or pain in the region of the hip/knee. All patients had radiographs consisting of anterior pelvis and 'frog lateral' views, and any abnormality suggesting an alternative diagnosis - that is, fracture of the hip, dysplasia - led to exclusion from the study. Almost all rheumatological disorders were referred directly to rheumatologists. Clinical details, investigations, and outcomes were recorded on a computer database. and

analysed. Four hundred and twenty six
Southampton SO9 4XY

G R Taylor

Correspondence to Mr Taylor.

Accepted 7 March 1994 
patients were admitted on 506 occasions with irritable hip, and 21 with sepsis either of the hip or adjacent pelvic bones. Other diagnostic groups included 23 patients with Perthes' disease and 37 with slipped epiphyses. The latter two diagnoses were made in all 60 patients from the admission radiographs and were therefore not included.

Initially, an audit of admission data for the patients with irritable hip and sepsis was derived from all admissions within the period 1 January 1988 to 31 December 1992. This was required for comparison with the ongoing prospective arm of the audit.

The clinical data included some previous episodes recorded before 1 January 1988. Clinical data were available for 418 of 426 (98\%) patients with irritable hip and all 21 patients with sepsis. Only one of the eight 'missing' patients had an inpatient stay greater than five days and correspondence shows that no specific diagnosis was made in this patient. It is therefore assumed that there was no case of bone or joint infection.

In each case, data were analysed for the first admission. Clinical details were recorded of subsequent admissions with the same or other problems in either hip and analysed separately. Particular attention was given to the few instances wherein apparently irritable hips were subsequently diagnosed to have a specific disease.

All investigations were recorded but few clinical details and laboratory results were reliably available for most patients. In addition to the record of age, sex, side, duration, date, and past medical history, the following information was recorded in more than $90 \%$ of all case notes: clinical data about pain, movement, and tenderness; temperature chart; full blood count; ESR; and radiograph reports. The following five factors were scored. (1) Pain/spasm was graded into three, severe, mild, or none, by comparing the entries of all doctors involved in the case. Severe was defined as the refusal to bear any weight through the affected limb, or spasm recorded as a significant loss of range of movement in more than one plane (usually including fixed flexion). Mild was defined as a loss of the extremes of movement, usually internal rotation and/or abduction. (2) Tenderness over the hip or adjacent pelvis. (3) Pyrexia $\geqslant 38^{\circ} \mathrm{C}$ (within 12 hours of admission). (4) ESR $\geqslant 20 \mathrm{~mm} /$ hour. (5) White cell count $\geqslant 11.0 \times 10^{9} / 1$.

The choice of pyrexia $\geqslant 38^{\circ} \mathrm{C}$ was made on the basis that low grade fevers were commonplace and this level of pyrexia was recorded in less than $20 \%$ of patients. The values of the latter two tests, both taken on the day of admission, represent the approximate upper limit of the laboratory normal range for children in this age range.

Patients were divided into four categories based on the number of criteria which they met. For this purpose, only severe pain/spasm was taken as a positive point towards categorisation; no weighting was attempted. The categories were compared for a variety of data, including length of stay, use of antibiotics/surgery, subsequent diagnosis, multiple admission, and the outpatient record of symptom resolution. The categories were defined on the number of positive criteria as: 0,0 criteria; 1,1 criteria; 2,2 criteria; and 3 , $\geqslant 3$ criteria.

\section{STATISTICS}

The statistical tests applied were Pearson's $\chi^{2}$ test with Yates's correction and the calculation of confidence intervals. Specificity, sensitivity, and predictive values for the diagnosis of sepsis were calculated.

\section{Results}

\section{AUDIT DATA}

The number of patients admitted with irritable hip in the period 1988-92 was 417. Nine patients were admitted in 1987, giving a total of 426 patients. There were $63(15 \%)$ patients with multiple admissions, giving a total of 143 multiple admissions. The total number of admissions was 506, with 471 between 1 January 1988 and 31 December 1992. The bed occupancy rate in 1988-92 was $1 \cdot 1 /$ day.

The number of patients with sepsis from 1 January 1988 to 31 December 1992 was 21, with 28 admissions and a bed occupancy rate of $0 \cdot 3 /$ day. Bed occupancy was based on overnight stay, with 'day cases' recorded as a stay of 0 days.

A total of $73 \%$ of the first admissions for irritable hip were for four days or less, with a range of 0 to 36 days. Sixteen (4\%) were admitted for at least 10 days. The patients with sepsis remained for a mean of 21 days (range 11-49 days).

The sex ratio for patients with irritable hip was 295 boys to 131 girls $(2 \cdot 25: 1)$ and did not significantly vary with the age at admission, the length of stay, or frequency of admission. The group with sepsis had a similar sex ratio of 14 boys to seven girls (2:1).

The origin of admission did not relate to diagnosis, severity, or length of stay.

\section{CLINICAL DATA}

The 21 patients with sepsis had an average age of 5.4 years, which was similar to the 5.8 years of the group with irritable hip, but included four younger than 6 months. The patients with irritable hip included only one child of this age, but with 14 aged 2 years or less.

Among the group with sepsis the site of infection was diagnosed with certainty in all but two cases and was as follows: hip, 10; ilium, 4; ?hip, 2; ischium, 1; sacroiliac joint, 3; and pubic ramus, 1 .

\section{HISTORICAL FACTORS}

The length of time that symptoms were reported before admission ranged widely in each group, with an average in patients with irritable hip of 4.1 days compared with 5.9 in the group with sepsis $(85 \%$ of patients with 


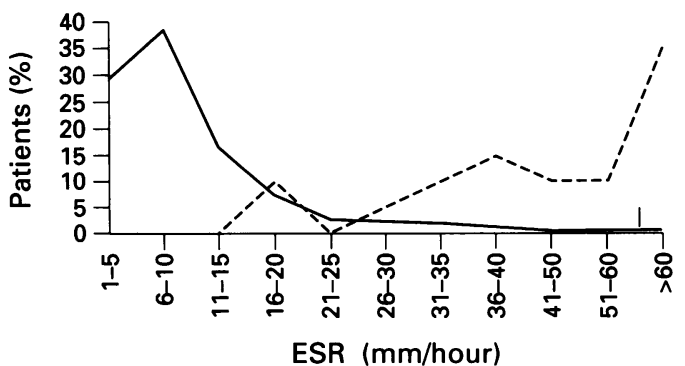

Distribution of ESR for patients with irritable hip and sepsis.

irritable hip and $62 \%$ of the patients with sepsis reported preadmission symptoms for three days or less). This was considered of no use in differentiating between the groups. It is interesting to note that the average length of preadmission symptoms in the patients with Perthes' disease who were admitted was 3.3 months.

A history of infection in the two weeks preceding admission was present in $135(32 \%)$ of the patients with irritable hip and six $(29 \%)$ of the patients with sepsis. In the main these were upper respiratory tract infections such as colds and otitis media.

Hip problems in infancy such as 'clicky hips' $(3 \%)$ and a general medical history for example, asthma (11\%) - bore no apparent relation to irritable hip. The rate of preadmission respiratory tract infection in the children with asthma was slightly higher than in patients with irritable hip but no asthma $(39 \%)$.

\section{EXAMINATION}

A limp was present in all children of walking age, except three patients with irritable hip, and was therefore of no discriminative value. Localised tenderness was recorded as positive in $72(17 \%)$ and negative in $193(46 \%)$ patients with irritable hip.

Clinical findings that appeared to differentiate were severe pain/spasm, local tenderness, and pyrexia of $\geqslant 38^{\circ} \mathrm{C}$ in the first 12 hours of admission.

\section{LABORATORY TESTS}

Investigations performed on the patients with irritable hip included: serological tests in 47

Table 1 Comparison of the clinical criteria for irritable hip and sepsis and their discriminative significance

\begin{tabular}{|c|c|c|c|}
\hline & $\begin{array}{l}\text { No (\%) with } \\
\text { irritable hip } \\
(n=418)\end{array}$ & $\begin{array}{l}\text { No (\%) with } \\
\text { 'septic' hip } \\
(n=21)\end{array}$ & Difference between groups for criteria \\
\hline $\begin{array}{l}\text { Hip pain/spasm } \\
\text { Severe } \\
\text { Mild } \\
\text { None }\end{array}$ & $\begin{array}{c}48(11 \cdot 5) \\
328(78 \cdot 5) \\
42(10)\end{array}$ & $\begin{array}{c}13(61 \cdot 9) \\
8(38 \cdot 1) \\
0(0)\end{array}$ & $\begin{array}{l}\text { Severe } \\
\chi^{2}=38 \cdot 4, \mathrm{df}=1, \mathrm{p}<0 \cdot 0001, \\
\text { difference }=50 \cdot 4, \mathrm{CI}=0.29 \text { to } 0 \cdot 71\end{array}$ \\
\hline $\begin{array}{l}\text { Tenderness } \\
\text { Present } \\
\text { Absent } \\
\text { Pyrexia }\left({ }^{\circ} \mathrm{C}\right)\end{array}$ & $\begin{array}{r}72(17 \cdot 2) \\
346(82 \cdot 8)\end{array}$ & $\begin{array}{r}18(85 \cdot 7) \\
3(14 \cdot 3)\end{array}$ & $\begin{array}{l}\text { Present } \\
\chi^{2}=53 \cdot 4, \mathrm{df}=1, \mathrm{p}<0 \cdot 0001, \\
\quad \text { difference }=68 \cdot 5, \mathrm{CI}=0.53, \text { to } 0.84 \\
\geqslant 38^{\circ} \mathrm{C}\end{array}$ \\
\hline $\begin{array}{l}\geqslant 38 \\
<38 \\
\text { ESR (mm/hour) } \\
\geqslant 20 \\
<20\end{array}$ & $\begin{array}{l}33(7 \cdot 9) \\
385(92 \cdot 1) \\
(\mathrm{n}=384) \\
39(10 \cdot 7) \\
327(89 \cdot 3)\end{array}$ & $\begin{array}{l}17(81) \\
4(19) \\
(\mathrm{n}=20) \\
19(90 \cdot 5) \\
2(9 \cdot 5)\end{array}$ & $\begin{array}{l}\chi^{2}=98 \cdot 6, \mathrm{df}=1, \mathrm{p}<0 \cdot 0001, \\
\text { difference }=32 \cdot 0, \mathrm{CI}=0 \cdot 20 \text { to } 0.46 \\
\geqslant 20 \mathrm{~mm} / \mathrm{h} \\
\chi^{2}=93 \cdot 1, \mathrm{df}=1, \mathrm{p}<0 \cdot 0001, \\
\text { difference }=79 \cdot 8, \mathrm{CI}=0.29 \text { to } 0.71\end{array}$ \\
\hline
\end{tabular}

$\chi^{2}=$ Pearson's $\chi^{2}$ test with Yates's correction; $C I=$ confidence interval; $\mathrm{df}=$ degrees of freedom. patients, midstream urine culture in 49 , and blood culture in 40 (all negative). Some were helpful in individual patients - for example, three positive urine cultures - but, in general, they rarely altered management.

The white cell count was recorded in $92 \%$ of patients with irritable hip and all of the patients with sepsis. The average in the former group was $9 \cdot 2 \times 10^{9} / 1$ and the latter $13 \cdot 2 \times 10^{9} / 1$. This value ranged widely in the group with sepsis, however, with only $38 \% \geqslant 12 \times 10^{9} / 1$ and this was often high in patients with otitis media. Raised white cell counts were predominantly related to neutrophilia.

The ESR was recorded on admission in $90 \%$ of patients with irritable hip (mean $10.9 \mathrm{~mm} / \mathrm{h}$ ) and $95 \%$ of the group with sepsis (mean $53.9 \mathrm{~mm} / \mathrm{h}$ ). The figure shows the distribution range. In this instance, using a cut off of $20 \mathrm{~mm} / \mathrm{h}$ ('abnormal' for all ages in the series $\left.^{29}\right) 10 \%$ of the patients with irritable hip and $90 \%$ of the patients with sepsis were included. Only $10 \%$ of all patients with an ESR of $\geqslant 20 \mathrm{~mm} /$ hour had a history of preceding infection, suggesting that an increased ESR cannot be explained simply on the basis of concurrent respiratory tract infection.

Table 1 details the data for the four chosen criteria and their individual discriminative significance. Table 2 shows the relation between the likelihood of increased length of stay, surgical intervention, and subsequent diagnosis with the number of criteria met within 12 hours of admission (categories 1-4). Table 3 shows the calculated specificity, sensitivity, and predictive values of the categories and component criteria.

\section{Discussion}

Our policy of admission for patients with painful hips has consumed considerable resources, with the irritable and sepsis groups together accounting for a bed occupancy of $1 \cdot 4 /$ day over the last five years. Such patients, with the exception of those with trauma, were the largest occupier of orthopaedic-paediatric beds in the five year period examined. The consequences of possible misdiagnosis necessitate prompt initial orthopaedic review and investigation, which requires imaging and is therefore impractical for general practitioners. It makes good sense to try and reduce admissions, however, providing 'safe' criteria can be established. The increase in outpatient attendance would not prove great as most patients already attend after admission (all the patients with sepsis and 290 of the patients with irritable hip attended on at least one occasion).

Firstly, the overall diagnostic performance for this five year period is considered. Every case of Perthes' disease admitted was diagnosed on the initial radiographs (a number of additional patients were diagnosed and treated entirely as outpatients). The clinical presentation may be similar and precede radiographic changes, however. Two patients with irritable hip presented with established 
Table 2 Categorisation of patients with irritable hip and sepsis according to the number of criteria met and in relation to outcome parameters

\begin{tabular}{|c|c|c|c|c|c|c|c|c|}
\hline \multirow[t]{2}{*}{$\begin{array}{l}\text { Category } \\
\text { No of criteria }\end{array}$} & \multicolumn{2}{|l|}{$\begin{array}{l}\text { Zero } \\
0\end{array}$} & \multicolumn{2}{|l|}{$\begin{array}{l}\text { One } \\
1\end{array}$} & \multicolumn{2}{|l|}{$\begin{array}{l}\text { Two } \\
2\end{array}$} & \multicolumn{2}{|l|}{$\begin{array}{l}\text { Three } \\
\geqslant 3\end{array}$} \\
\hline & Irritable & Septic & Irritable & Septic & Irritable & Septic & Irritable & Septic \\
\hline $\begin{array}{l}\text { No (\%) cases } \\
\text { Mean length stay (days) } \\
\text { No of patients needing an operation } \\
\text { No of subsequent diagnoses }\end{array}$ & $\begin{array}{l}278(67) \\
3 \cdot 3 \\
1 \\
12\end{array}$ & $\begin{array}{l}0(0) \\
0 \\
0\end{array}$ & $\begin{array}{l}101(24) \\
4 \cdot 3 \\
1 \\
2\end{array}$ & $\begin{array}{c}1(5) \\
26 \\
0\end{array}$ & $\begin{array}{l}29(7) \\
4 \cdot 3 \\
0 \\
0\end{array}$ & $\begin{array}{c}2(10) \\
13 \cdot 5 \\
1\end{array}$ & $\begin{array}{l}10(2) \\
7 \cdot 9 \\
4 \\
0\end{array}$ & $\begin{array}{l}18(86) \\
21 \cdot 6 \\
15\end{array}$ \\
\hline
\end{tabular}

Perthes' disease, one six months and the second one month after discharge. The latter developed Perthes' disease changes in the opposite hip. Neither showed any features to suggest that they were atypical. The incidence of this 'association' varies from 0 to $17 \%$ in published work; the larger values are reported from small series. ${ }^{381013233031}$ Interestingly, three other patients with irritable hip who had isotope scans for prolonged symptoms displayed 'cold' areas, but never developed frank radiographic changes. This has been described as Perthes' disease grade 0 by Royle, and probably accounts for a small, unrecognised subgroup of irritable hips. 152631 There were two cases of slipped epiphysis which were not apparent on the admission radiograph, but because of their age and presentation the diagnosis was suspected clinically. An increased uptake of isotope at the growth plate confirmed them as 'pre-slips' and both resolved after single screw fixation. Only one patient admitted with a diagnosis of irritable hip was subsequently shown to have a rheumatological disorder (pauciarticular juvenile chronic arthritis); patients with such disorders were generally referred directly to paediatricians or rheumatologists on clinical grounds.

Therefore, the principal differential diagnosis was between irritable hip and sepsis. In practice it took no longer than 24-48 hours to confirm the diagnosis and initiate treatment in all but four cases of the latter. Three had localised osteomyelitis of the ilium and the fourth of the sacroiliac joint. The general picture in such patients differed from the patients with septic arthritis, with less spasm and discrete tenderness separate from the hip. Delays that occurred in diagnosing septic arthritis were due to factors such as transfer from other hospitals and pretreatment with antibiotics, blunting the clinical signs.

Among 418 children admitted with irritable hip, only six had aspiration/arthrotomy. Two aspirations were dry, an arthrogram being performed to establish needle position. In

Table 3 Specificity, sensitivity, and predictive value for the diagnosis of sepsis in the two groups according to the number of criteria met and the component criteria chosen

\begin{tabular}{llll}
\hline No of criteria & $\begin{array}{l}\text { Specificity } \\
(\%)\end{array}$ & $\begin{array}{l}\text { Sensitivity } \\
(\%)\end{array}$ & $\begin{array}{l}\text { Predictive } \\
\text { value (\%) }\end{array}$ \\
\hline 1 & 67 & 100 & 13 \\
2 & 91 & 95 & 34 \\
3 & 98 & 86 & 64 \\
4 & 99 & 38 & 67 \\
Severe hip spasm/pain & 89 & 62 & 21 \\
Tenderness & 82 & 86 & 19 \\
Pyrexia $\geqslant 38^{\circ} \mathrm{C}$ & 92 & 81 & 34 \\
ESR $\geqslant 20 \mathrm{~mm} /$ hour & 91 & 86 & 32 \\
\hline
\end{tabular}

retrospect it would have been feasible to have used ultrasound in these patients to determine the presence or absence of an effusion. Both were carried out as emergency procedures and isotope scans performed within 48 hours postoperatively were negative. The remaining four had positive aspirations and immediate arthrotomy. The turbid fluid obtained in these patients was negative on Gram staining and culture (none was given antibiotics preoperatively). The finding of such sterile aspirates has been reported by several workers who have aspirated patients with an irritable hip. 27101318 Follow up showed no radiographic changes to confirm local osteomyelitis and therefore the diagnosis was considered to be transient synovitis, except in one child who did not improve and was subsequently found to have acetabular fibrous dysplasia.

The above cases include all patients who developed a specific disorder to account for their irritable hip symptoms, even when this was diagnosed at a subsequent admission. It also includes all 10 with abnormal isotope scans, except for two which showed 'mild, diffuse increased uptake in the hip; a pattern compatible with transient synovitis'.192324 26

Table 1 categorises these patients according to four criteria. These have been chosen because they are reliably recorded in most case notes and significantly distinguish between the two groups. By definition, they select those children with severe symptoms, who might benefit from admission regardless of their disorder. Had all children in category 2 been admitted, this would have given a total of 49 of $447(11 \%)$ and included all the group with sepsis except for one (who had been referred from a hospital abroad with a diagnosis of septic arthritis, having taken a 10 day course of antibiotics). Assuming a more cautious approach and admitting all patients in category 2 and those with severe spasm, then $63(15 \%)$ patients would have been admitted. These would have included all the irritable hip group who had an operation, except the patient with acetabular fibrous dysplasia, but would have excluded two patients who later returned with Perthes' disease and three patients with radiologically negative Perthes' disease. These patients had neither long periods of preadmission symptoms nor a prolonged stay (on their first admission), and were investigated for recurrent or persistent symptoms when reviewed as outpatients. No evidence was found to support admission as an aid to predicting or averting future disease.

The principal source of error was likely to have been in the collection of clinical details. The ward record of admissions and 'presenting 
disorder'/discharge diagnosis was almost complete (any unclear diagnosis was checked by a review of the notes) and so few patients will have been missed. Case notes were located in $98 \%$ and the clinical details obtained by assessing all relevant entries, including the general practitioner or accident and emergency referral letters, as well as the inpatient notes. Pyrexia was the highest recorded from any of the above in the first 12 hours. Differentiation of the severity of pain/spasm into the three grades was surprisingly straightforward from comparison of different doctors' entries. Tenderness was less certain, though there was generally mention of it as either positive or negative. Laboratory data were verified from the computer records whenever there was doubt.

In conclusion, this audit suggests that most children with painful hips may be safely managed as outpatients after examination and simple investigation as 'day cases'. Using the proposed criteria, it would be possible to reduce the number of bed days occupied by such patients in our unit by approximately $85 \%$, with a relatively small increase in clinic attendance. This would prove beneficial both in terms of resources and for the children, who are often reluctant patients! Specialised imaging may be reserved for the small proportion of severe, prolonged, or recurrent cases.

It is clear from table 3 that the best profile for specificity, sensitivity, and predictive value was given by category 3 , but we have chosen at least category 2 as part of our admission protocol to reduce the risk of missing a patient with sepsis at the expense of a relatively modest increase in the numbers admitted.

The retrospective nature of this work demands prospective confirmation before any recommendations can be made. The following admission protocol is currently being tested in our unit: (a) age 18 months or less; (b) painful hip treated with antibiotics; (c) patients meeting two or more of the following criteria, or with severe pain/spasm alone - severe pain/spasm, local tenderness, and pyrexia $\geqslant 38^{\circ} \mathrm{C}$, and ESR $\geqslant 20 \mathrm{~mm} /$ hour; and (d) social concerns.

In theory, this protocol would have resulted in the admission of all our patients with sepsis over the past five years and saved 1520 bed days (not allowing for the few presenting late in the evening).
1 Butler RW. Transitory arthritis of the hip in childhood. $B M F$ 1933; i: 951-4.

2 Adams JA. Transient synovitis of the hip in children. 7 Bone foint Surg $\mathrm{Br} 1963$; 45: 471-6.

3 Landin AL, Danielsson LG, Wattsgard C. Transient synovitis of the hip. 7 Bone foint Surg Br 1987; 69: 238-42.

4 Briggs RD, Baird KS, Gibson PH. Transient synovitis of the hip joint. $\mathcal{F} R$ Coll Surg Edinb 1990; 35: 48-50.

5 Bickerstaff DR, Neal LM, Brennan PO, Bell MJ. An investigation into the etiology of irritable hip. Clin Pediatr (Phila) 1991; 30: 353-6.

6 Lovett RW, Morse JL. A transient or ephemeral form of hip disease, with a report of cases. Boston Medical and Surgical fournal 1892; 127: 161 .

7 de Valderrama JA. The 'observation hip' syndrome and its late sequelae. F Bone foint Surg Br 1963; 45: 462-70.

8 Sharwood PF. The irritable hip syndrome in children. Acta Orthop Scand 1981; 52: 633-8.

9 Vidigal EC, Da Silva OL. Observation hip. Acta Orthop Scand 1981; 52: 191-5.

10 Hauesien DC, Weiner DS, Weiner SD. The characterisation of 'transient synovitis of the hip' in children. $\mathcal{F}$ Pediatr Orthop 1986; 6: 11-7.

11 Hardinge $K$. The etiology of transient synovitis of the hip in childhood. F Bone foint Surg Br 1970; 52: 100-7.

12 Sainsbury CPQ, Newcombe RG, Essex-Cater A. Irritable hips; relationship with trauma [letter]. Lancet 1986; i: 220.

13 Erken EHW, Katz K. Irritable hip and Perthes' disease. f Pediatr Orthop 1990; 10: 322-6.

14 Kunnamo I, Kallio P, Pelkonen P, Hovi T. Clinical signs and laboratory tests in the differential diagnosis of arthritis in children. Am F Dis Child 1987; 141: 35-40.

15 Wingstrand H. Transient synovitis of the hip in the child. Acta Orthop Scand 1986; 57 (suppl 219): 5-61.

16 Nachemson A, Scheller S. A clinical and radiological follow-up study of transient synovitis of the hip. Acta Orthop Scand 1969; 40: 479-500.

17 Bickerstaff DR, Neal LM, Booth AJ, Brennan PO, Bell MJ. Ultrasound examination of the irritable hip. $\mathcal{F}$ Bone foint Surg Br 1990; 72: 549-53.

18 Kallio P, Ryoppy S, Jappinen S, Siponmaa A, Jaaskelainen $\mathrm{J}$, Kunnamo I. Ultrasonography in hip disease in children. Acta Orthop Scand 1985; 56: 367-71.

19 Egund N, Wingstrand H, Forsberg L, Forsberg L, Petterson $H$, Sunden G. Computed tomography and ultrasonography for diagnosis of hip joint effusion in children. Acta Orthop Scand 1986; 57: 211-5.

20 McGoldrick F, Bourke T, Blake N, Fogarty E, Dowling F, Regan B. Accuracy of sonography in transient synovitis. f Pediatr Orthop 1990; 10: 501-3.

21 Bialik V, Volpin G, Jerushalmi J, Stein H. Sonography in the diagnosis of painful hips. Int Orthop 1991; 15: 155-9.

22 Futami T, Kasahara Y, Suzuki S, Ushikubo S, Tsuchiya T. Ultrasonography in transient synovitis and early Perthes' disease. F Bone foint Surg Br 1991; 73: 635-9.

23 Calver R, Venugopal V, Dorgan J, Bentley G, Gimlette T. Radionuclide scanning in the early diagnosis of Perthes' disease. F Bone foint Surg Br 1981; 63: 379-82.

24 Carty H, Maxted M, Fielding JA, Gulliford P, Owen R. Isotope scanning in the 'irritable hip syndrome'. Skeletal Radiol 1984; 11: 32-7.

25 Gordon I, Peters AM, Nunn R. The symptomatic hip in childhood: scintigraphic findings in the presence of a normal radiograph. Skeletal Radiol 1987; 16: 383-6.

26 Royle SG, Galasko CSB. The irritable hip. Scintigraphy in 192 children. Acta Orthop Scand 1992; 63: 25-8.

27 Illingworth CM. 128 Limping children with no fracture, sprain, or obvious cause. Clin Pediatr (Phila) 1978; 17: 139-42.

28 McCarthy PL, Wasserman D, Spiesel Z, Dolan TF, Jekel JF. Evaluation of arthritis and arthralgia in the pediatric patient. Clin Pediatr (Phila) 1980; 19: 183-90.

29 Hollinger NF, Robinson SJ. A study of the erythrocyte sedimentation rate for well children. $\mathcal{f}$ Pediatr 1953: 42: 304-19.

30 Jacobs BW. Synovitis of the hip in children and its significance. Pediatrics 1971; 47: 558-66.

31 Kallio P, Ryoppy S, Kunnamo I. Transient synovitis and Perthes' disease. F Bone foint Surg Br 1986; 68: 808-11. 